\title{
The effect of morphine preexposure on the acquisition of morphine-induced taste aversions: A nonassociative effect
}

\author{
ANTHONY L. RILEY, ROBERT J. DACANAY, and JOHN P. MASTROPAOLO \\ The American University, Washington, D.C.
}

\begin{abstract}
In Experiment 1, the amount of time rats spent engaged in a range of behaviors was recorded immediately prior to and following the intraperitoneal administration of morphine sulfate $(6 \mathrm{mg} / \mathrm{kg})$ or distilled water. No behavioral differences were observed between these groups. In Experiment 2, preexposure to this low dose of morphine attenuated the subsequent acquisition of a morphine-induced taste aversion independent of the similarity of the preexposure and conditioning environments. These results with a dose of morphine that does not produce any behavioral effects, which in turn could potentially mask associative conditioning during preexposure, confirm that the attenuating effects of morphine preexposure on taste aversion learning are nonassociative.
\end{abstract}

Recently, both nonassociative (Riley, Jacobs, \& LoLordo, 1976) and associative (Batson \& Best, 1979; Braveman, 1979) mechanisms have been presented as explanations for the rat's failure to acquire a conditioned taste aversion following extensive preexposure to the aversion-inducing agent (unconditioned stimulus, UCS). In relation to the nonassociative interpretation of the UCS preexposure effect, it has been suggested that various pharmacokinetic and pharmacodynamic changes that occur during chronic drug exposure reduce the effects of the drug to a level insufficient to condition a subsequent aversion (Cannon, Baker, \& Berman, 1977; Dacanay \& Riley, 1982; Domjan \& Siegel, 1983; Gamzu, 1977; Jacobs, Zellner, LoLordo, \& Riley, 1981; Riley et al., 1976). In relation to the associative position, it has been suggested that environmental and injection cues that accompany the administration of the drug during chronic drug preexposure become associated with the drug and then block (Kamin, 1969; Randich \& LoLordo, 1979) the ability of other cues, for example, taste, to become associated with the drug when taste aversion conditioning is subsequently attempted in their presence (Batson, 1983; Batson \& Best, 1979; Dacanay \& Riley, 1982; Rudy, Iwens, \& Best, 1977; Willner, 1978).

While considerable attention has been focused on determining which of these two explanations best accounts for the effects of prior drug exposure on taste aversion learning (see above), Dacanay and Riley (1982) have recently suggested that the mechanism underlying the UCS preexposure effect, that

The authors would like to thank J. Risser and C. Senger for their technical assistance. Requests for reprints should be sent to Anthony L. Riley, Psychopharmacology Laboratory, Department of Psychology, The American University, Washington, DC 20016. is, either nonassociative or associative, may be dependent upon the specific drug used during preexposure and conditioning. In their study, they demonstrated that preexposure to $\mathrm{LiCl}$ attenuated the subsequent acquisition of $\mathrm{LiCl}$-induced taste aversions only if preexposure and conditioning occurred in the same environments (see also Batson, 1983, and Batson \& Best, 1979). Because blocking should occur only when taste aversion conditioning is attempted in the environment in which the drug has been preexposed, this environment-specific UCS preexposure effect with $\mathrm{LiCl}$ is consistent with an associative interpretation. On the other hand, morphineinduced taste aversions were attenuated by morphine preexposure in subjects preexposed and conditioned in the same environment and in subjects preexposed and conditioned in different environments (see also Domjan \& Siegel, 1983, and Stewart \& Eikelboom, 1978). Again, since blocking should be evident only when conditioning is attempted in the environment in which preexposure had been given, the effects of morphine preexposure are not consistent with an associative account. That the degree of attenuation was identical for the two morphine-preexposed groups further suggests that blocking made no contribution to the attenuating effects of morphine preexposure on morphine-induced taste aversions.

Although there appears to be no evidence that blocking contributes to the morphine-induced preexposure effect, it should be noted that the dose of morphine given during preexposure and conditioning by Dacanay and Riley (1982, Experiment 2) was 40 $\mathrm{mg} / \mathrm{kg}$ a dose that produces profound and longlasting behavioral catatonia (Babbini \& Davis, 1972; Babbini, Gaiardi, \& Bartoletti, 1979; Heft, Daniels, Buller, \& Riley, 1981; Schnur, Bravo, Trujillo, \& Rocha, 1983). It is quite possible that the behav- 
ioral depression induced by this high dose of morphine prevented the rat from acquiring any information about environmental cues or their association with the effects of morphine. Without this association, blocking could not occur when taste aversion conditioning was subsequently attempted. This possibility of an interaction between the dose of morphine and the probability of environmental conditioning in the UCS preexposure effect is supported in a range of other classical conditioning designs demonstrating clear environmental-morphine associations when lower doses of morphine are administered in the presence of specific environmental cues (Siegel, 1976, 1978; Siegel, Hinson, \& Krank, 1978; see also Sklar \& Amit, 1978).

If the behavioral catatonia induced by high doses of morphine prevents the animal from acquiring associations between the environmental cues and morphine during morphine preexposure (see Dacanay \& Riley, 1982), then environmental conditioning might occur when preexposure is given to a dose of morphine that produces no behavioral catatonia. As such, both nonassociative and associative mechanisms might affect the subsequent acquisition of taste aversions following morphine preexposure. This prediction was tested in Experiments 1 and 2.

\section{EXPERIMENT 1}

Before investigating the possibility that blocking might be detected if a lower dose of morphine is given during preexposure, two issues must be considered. While the dose of morphine must be weak enough to produce no catatonia during preexposure, it must be sufficient to induce a conditioned taste aversion to which the attenuating effects of drug preexposure can be compared.

When morphine has been examined within a taste aversion paradigm, high doses are typically given during conditioning (Cappell, LeBlanc, \& Herling, 1975; Farber, Gorman, \& Reid, 1976; Jacobs et al., 1981; Riley, Jacobs, \& LoLordo, 1978; Stewart \& Eikelboom, 1978). Doses as low as $6 \mathrm{mg} / \mathrm{kg}$, however, have been reported to produce conditioned taste aversions (Cappell, LeBlanc, \& Endrenyi, 1973). Although such a low dose would appear to be appropriate for the assessment of blocking as a mechanism for the effects of morphine preexposure (see above), it is unclear if $6 \mathrm{mg} / \mathrm{kg}$ induces behavioral catatonia. Although catatonia is typically reported to occur with relatively high doses of morphine, for example, greater than $30 \mathrm{mg} / \mathrm{kg}$ (Heft et al., 1981; Babbini \& Davis, 1972), some degree of catatonia is still evident with doses as low as $10 \mathrm{mg} / \mathrm{kg}$ (Heft et al., 1981; Schnur et al., 1983). Therefore, before examining the effects of preexposure to $6 \mathrm{mg} / \mathrm{kg}$ morphine sulfate on the subsequent acquisition of morphine-induced taste aver- sions, one must first determine that this specific dose does not produce behavioral catatonia. To this end, the following experiment measured the percentage of time rats spent engaging in five different behavioral categories before and after injections of $6 \mathrm{mg} / \mathrm{kg}$ of morphine sulfate or distilled water. The procedure of Experiment 1 was identical to Phase 1 and Phase 2 in Experiment 2, to allow comparison of the data between these two experiments.

\section{Method}

\section{Subjects}

The subjects were 10 experimentally naive male rats of LongEvans descent, approximately 90 days of age at the beginning of the experiment.

\begin{abstract}
Apparatus
Drug exposures were given in 10 identical Plexiglas holding bins $(29 \times 18.5 \times 12.5 \mathrm{~cm})$, the floors of which were lined with approximately $1 \mathrm{~cm}$ of wood chips. Fluids were made available in these bins via graduated Nalgene drinking tubes located on overhead stainless steel grids that served as the ceiling of the bins. The bins were located in a room adjacent to the room in which the animals' home cages were located. Both rooms were maintained on a 12 $\mathrm{h}$-light/12-h-dark cycle (lights on at $0800 \mathrm{~h}$ ) and at an ambient temperature of $24^{\circ}-25^{\circ} \mathrm{C}$. A radio provided constant ambient
\end{abstract} noise in the room housing the Plexiglas bins.

\section{Procedure}

Phase 1: Habituation. Prior to the initiation of this phase, the rats were deprived of water and given ad-lib access to food. On the following day (Day 1), they were given 20 -min access to water in the home cage. This habituation procedure was repeated for 13 consecutive days, at which point all rats were approaching and drinking from the tube within $2 \mathrm{sec}$ of its presentation.

Phase 2: Drug exposure. At $1200 \mathrm{~h}$ on the 1 st day of this phase (Day 14), all rats were placed in the distinctive Plexiglas bins and given 20 -min access to water. No food was available at this time. During this 20-min period, two 1-min observations were made of each animal (the order of observations for each rat was randomly determined at the beginning of the session). The behavior of each rat was recorded according to five categories (see Table 1 for these behavioral categories) by a single experimenter, sitting approximately $5 \mathrm{ft}$ in front of the bins. The experimenter recorded the time devoted to these behaviors by activating mercury switches mounted on a hand-held board connected to the input of a computer interface (Interface 80; Alpha Products), which in turn was connected to a TRS-80 Model III microcomputer (Tandy Corporation). The computer program to record data was written in BASIC.

At the end of the 20-min observation period, the water tubes

Table 1

Behavioral Categories Recorded During the 20-min Preand Postinjection Period

Catatonia No movement, accompanied by a rigid body posture; slow breathing; erect tail; eyes wide open and bulging

Immobility No movement, but lacking the rigidity of catatonia; breathing normal or slightly accelerated; tail flacid; eyes open but not bulging

Motor Walking; jumping; climbing; rearing; stretching; burrowing; circling

Grooming Licking, biting, or scratching body

Chewing Chewing of wood chips 
were removed from the bins and randomly selected rats were given an equivolume intraperitoneal (ip) injection of either $6 \mathrm{mg} / \mathrm{kg}$ morphine sulfate drawn from a concentration of $10 \mathrm{mg} / \mathrm{ml}$ (Group $M, n=5$ ) or the distilled water vehicle (Group $W, n=5$ ). Immediately following the injection, all rats were returned to the distinctive bins, where they were observed for an additional $20 \mathrm{~min}$ according to the procedure described above. At the end of the second observation period, all rats were returned to their home cages. On the following 3 days, all rats were given 20 -min access to water in the home cage followed immediately by an ip injection of distilled water. This alternating pattern of drug injection/water recovery was repeated until all rats had received five morphine or vehicle injections.

\section{Results}

All statistical inferences were based on an analysis of variance, and group differences were determined using the least significant difference test (Roscoe, 1975). All reported significant differences are at the $\mathrm{p}<.05$ level, two-tailed.

Figure 1 presents the percentage of the observed time spent for each group in motor activity, immobility, grooming, and chewing on the first injection day. As can be seen in the figure, prior to the injection both groups spent the majority of their observed time engaged in motor activity $(53 \%$ and $54 \%$ for Groups $M$ and $W$, respectively). Although grooming, immobility, and chewing were recorded, the combination of these behaviors occurred less than $4 \%$ of the observed time. There were no significant differences between Groups $M$ and $W$ on any behavior during this 20 -min preinjection observation period.

Following the injection, both groups decreased the amount of time spent in motor activity. Immobility increased for both groups, however, occurring approximately $51 \%$ and $60 \%$ of the available time for Groups $M$ and $W$, respectively (see Figure 1 ). As in the preinjection period, grooming and chewing occurred infrequently. There were no significant differences between Groups $M$ and $\mathbf{W}$ on any behavior during this postinjection period. Catatonia was not

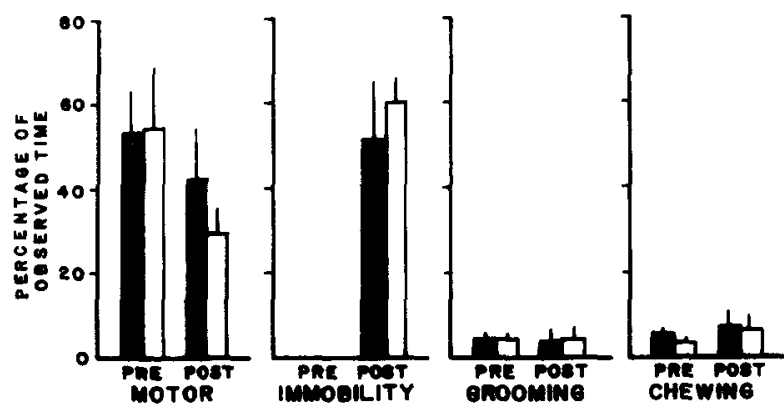

Figure 1. Mean percent of the observed time spent in motor activity, immoblity, grooming, and chewing in the $20 \mathrm{~min}$ prior to and following the injection on Day 1 for Groups $M$ (shaded bars) and $W$ (unshaded bars). Vertical lines indicate the SEM.

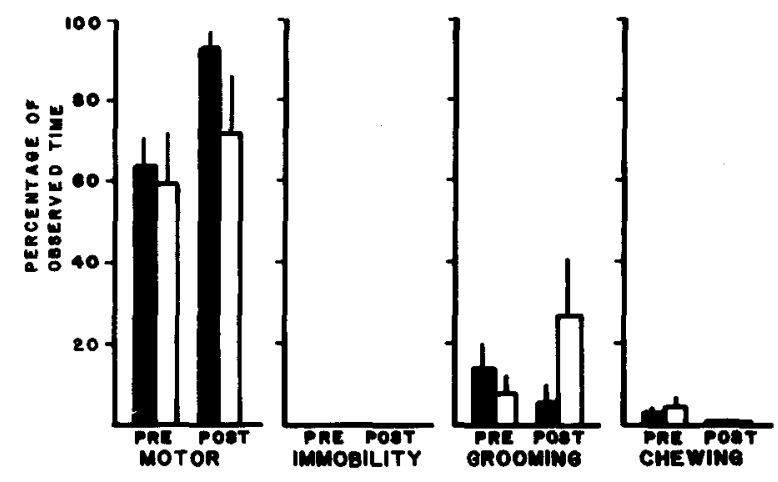

Figure 2. Mean percent of the observed time spent in motor activity, immobllity, grooming, and chewing in the 20 min pror to and following the injection on Day 5 for Groups $M$ (shaded barn) and W (unshaded bars). Vertical lines indicate the SEM.

evident at any time before or after injection for either of the two groups on this initial injection day.

Over repeated injections, rats in both groups continued to spend most of their preinjection time engaged in motor activity. For example, on the final injection day, Groups $\mathbf{M}$ and $\mathbf{W}$ displayed motor activity $64 \%$ and $57 \%$ of their available time, respectively, with the remaining behaviors continuing to occur infrequently. On this day, there were no differences between Groups $M$ and $W$ on any behavior during the preinjection period.

Although in the 20-min period following the first injection both groups primarily displayed immobility, with repeated injections immobility significantly decreased during this postinjection period. On the other hand, activity during this period increased over repeated injections. For example, following the final injection, Groups $M$ and $W$ were active $93 \%$ and $72 \%$ of the available time, respectively. The remaining behaviors continued to occur at a low level. As above, Groups $M$ and $W$ did not differ on any behavioral measure on this final injection day. Catatonia, again, was not evident before or after the injection for either group. These patterns in behavior on the final injection day are illustrated in Figure 2.

Finally, there were no significant differences in water consumption between groups at any point during the injection period, with both groups drinking a daily mean of approximately $14 \mathrm{ml}$ of water.

\section{EXPERIMENT 2}

Although rats that received $6 \mathrm{mg} / \mathrm{kg}$ of morphine sulfate displayed a range of specific behaviors prior to and following the injection, at no point did the behavior of these rats differ from that of control rats. Accordingly, if the failure to demonstrate blocking following morphine preexposure in Dacanay and Riley (1982) was due to the fact that during preex- 
posure morphine produced a number of behavioral effects, for example, catatonia, which prevented the learning of an association between the environmental cues and the effect of morphine, then blocking might affect taste aversion conditioning when preexposure is given to $6 \mathrm{mg} / \mathrm{kg}$ of morphine sulfate. This prediction was tested in Experiment 2.

\section{Method}

\section{Subjects}

The subjects were 24 experimentally naive rats of the same age, sex, and strain and maintained under the same conditions as in Experiment 1.

\section{Apparatus}

The home cage and drug exposure environments were identical to those previously described.

\section{Procedure}

Phase 1: Habituation. Prior to the intiation of this phase, the rats were deprived of water and given ad-lib access to food. On the following day (Day 1), they were given 20-min access to water in the home cage. This habituation procedure was repeated for 13 consecutive days, at which point all rats were approaching and drinking from the tube within $2 \mathrm{sec}$ of its presentation. This procedure insured that fluid consumption during the 20 -min access period was stable prior to the initiation of drug preexposure.

Phase 2: Drug preexposure. At $1200 \mathrm{~h}$ on the $1 \mathrm{st}$ day of this phase (Day 14), all rats were placed in the Plexiglas bins and were given 20 -min access to water. No food was available at this time. Immediately following access to water, differential treatment was administered to two groups of rats matched on water consumption, Groups $M$ and $W(n=12$ per group). Subjects in Group $M$ were given an ip injection of $6 \mathrm{mg} / \mathrm{kg}$ of morphine sulfate $(M)$ and were returned to the Plexiglas bin for 20 additional minutes. At the end of this period, they were returned to their home cages. Subjects in Group W were treated similarly, except that following water access these rats were given an equivolume ip injection of the distilled water vehicle (W). On the following 3 days, to allow for sufficient recovery from the effects of morphine prior to the next injection, all rats were given 20 -min access to water in the home cage followed immediately by an ip injection of distilled water. Distilled water injections administered at this time insured that handling and injection cues were nonpredictive of the effects of morphine. This alternating pattern of drug preexposure/water recovery was repeated until all rats had received five complete cycles.

Phase 3: Taste aversion conditioning. On the day following the last water-recovery session, Groups $\mathbf{M}$ and $\mathbf{W}$ were each randomly divided into two groups of subjects. Rats in Groups ME and WE ( $n=6$ per group) were placed in the Plexiglas bins (distinctive environment, E) and were given 20-min access to a novel saccharin solution $(0.1 \% \mathrm{w} / \mathrm{v}$ sodium saccharin, Fisher purified). Immediately following saccharin access, the rats in each of these groups were given injections of morphine sulfate $(6 \mathrm{mg} / \mathrm{kg})$ and then returned to the Plexiglas bins for an additional $20 \mathrm{~min}$. At the end of this period, they were returned to their home cages. Subjects in Groups $\mathrm{MH}$ and WH ( $=6$ per group) were treated similarly, except that they were given 20 -min access to saccharin in the home cage (H) immediately prior to receiving an ip injection of morphine. On the following 3 days, all rats were given 20-min access to water in the home cage, followed immediately by an ip injection of distilled water. This alternating pattern of conditioning/ water recovery was repeated until all rats had received three complete cycles. On the day following the last water-recovery session, all rats were given $20-\mathrm{min}$ access to saccharin in their respective conditioning environments in a final one-bottle aversion test.

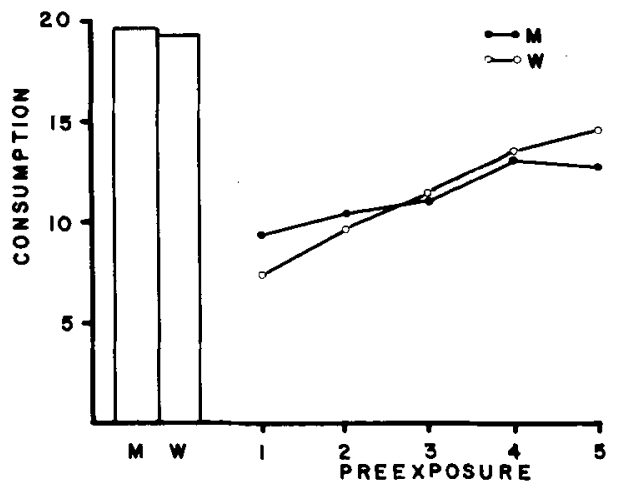

Figure 3. Mean water consumption ( $\mathrm{ml}$ ) for $G$ roups $M$ and $\mathbf{W}$ in the home cage during the 3 days prior to drug preexposure (open bars) and in the Plexiglas bins during the preexposure phase.

\section{Results}

\section{Phase 1: Habituation}

Over the water adaptation days, the rats gradually increased consumption of water, drinking a mean of approximately $19 \mathrm{ml}$ on each of the final 3 days of water adaptation.

\section{Phase 2: Drug Preexposure}

On Day 1 of the preexposure phase, when all rats were given their 20-min access to water in the distinctive environment, both Groups $\mathrm{M}$ and $\mathrm{W}$ decreased consumption below their previous day's water baseline in the home cage. Figure 3 illustrates this decrease in consumption on the first exposure to the distinctive environment (see Baseline and Preexposure 1).

With repeated access to water in the distinctive environment, both groups showed a slight, but nonsignificant, increase in consumption, although neither group approximated its home-cage water baseline (see Figure 3). At no point during this preexposure phase did Groups $\mathrm{M}$ and $\mathrm{W}$ differ in their consumption of water.

During the water recovery sessions following each preexposure injection, consumption for both groups returned to the water baseline.

\section{Phase 3: Taste Aversion Conditioning}

Rats given control injections during the preexposure phase (Groups WH and WE) showed a slight, but nonsignificant, decrease in saccharin consumption following the first saccharin-morphine pairing during conditioning. With repeated conditioning trials, these rats significantly decreased saccharin consumption, drinking less than 10 (Group WH) and $7 \mathrm{ml}$ (Group WE) of saccharin, respectively, on the final aversion test. There were no differences between Groups WE and WH in saccharin consumption over the repeated conditioning trials or on the 


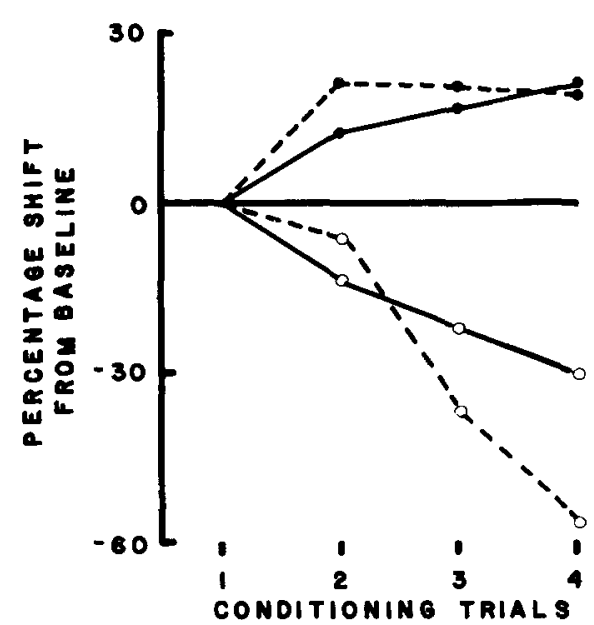

Figure 4. Percentage shift in saccharin consumption from the initial saccharin baseline over repeated conditioning trials for groups preexposed to morphine (solid circles) or water (open circles) and conditioned in the environment (solid line) or the home cage (dashed line).

final aversion test. These patterns of consumption of saccharin over conditioning trials are illustrated in Figure 4.

Rats given morphine injections during preexposure (Groups ME and MH) showed a slight, but nonsignificant, increase in saccharin consumption following the first saccharin-morphine pairing. With repeated conditioning trials, these rats continued to drink the saccharin solution, consuming approximately $19 \mathrm{ml}$ (Group MH) and $17 \mathrm{ml}$ (Group ME) of saccharin, respectively, on the final aversion test. There were no differences between Groups ME and MH in the amount of saccharin consumed over the repeated conditioning trials or on the final aversion test (see Figure 4).

Although there was no difference in saccharin consumption between the preexposed and nonpreexposed groups after the first saccharin-morphine pairing, the rats preexposed to distilled water drank significantly less saccharin than did the morphinepreexposed rats on each of the remaining conditioning trials and on the final aversion test (see Figure 4). This difference between preexposed and nonpreexposed rats was independent of the similarity of the preexposure and conditioning environments; that is, each of the groups preexposed to morphine (Groups $\mathrm{ME}$ and $\mathrm{MH}$ ) drank significantly more than its nonpreexposed control (Groups WE and WH).

\section{DISCUSSION}

It is clear from the data that animals preexposed to $6 \mathrm{mg} / \mathrm{kg}$ morphine sulfate displayed an attenuated morphine-induced taste aversion independent of the similarity of the preexposure and conditioning environments. More importantly, the degree of at- tenuation was similar for the two morphine-preexposed groups. Together, these results indicate that the attenuating effects of preexposure to $6 \mathrm{mg} / \mathrm{kg}$ on morphine-induced taste aversions are not due to blocking (see also Domjan \& Seigel, 1983) and confirm the general conclusion that blocking does not contribute to the morphine-induced UCS preexposure effect (Dacanay \& Riley, 1982; Domjan \& Seigel, 1983; Stewart \& Eikelboom, 1978).

Although blocking may not be contributing to the attenuation of conditioned aversions following morphine preexposure, the exact mechanism responsible for the attenuation remains unclear. Previously, we have suggested that the morphine-induced preexposure effect is due to some unspecified pharmacological change that occurs during drug preexposure (see Dacanay \& Riley, 1982). Although it is certainly possible that any one of a number of pharmacodynamic or pharmacokinetic changes may mediate the effects of chronic morphine exposure on taste aversion learning, there is seldom an examination or an independent assessment of these changes (for exceptions see Batson, 1983; Cannon et al., 1977; Stewart \& Eikelboom, 1978). Since these pharmacological changes are offered as the mechanism for the UCS preexposure effect based primarily on the fact that the attenuation is not dependent upon the similarity of the preexposure and conditioning environments, the most one should conclude about the mechanism underlying the effect of morphine preexposure on taste aversion learning is that it is nonassociative in nature.

\section{REFERENCES}

Babbini, M., \& DAvis, W. (1972). Time-dose relations for locomotor activity effects of morphine after acute or repeated treatment. British Journal of Pharmacology, 46, 213-224.

Babbini, M., Gainadi, M., \& Bartoletti, M. (1979). Dosetime motility effects of morphine and methadone in naive or morphinized rats. Pharmacology Research Communication, 11, 809-816.

Batson, J. (1983). Effects of repeated lithium injection on temperature, activity, and flavor conditioning in rats. Animal Learning \& Behavior, 11, 199-204.

Batson, J., \& Best, P. (1979). Drug-preexposure effects in flavor-aversion learning: Associative interference by conditioned environmental stimuli. Journal of Experimental Psychology: Animal Behavior Processes, 5, 273-283.

Braveman, N. (1979). The role of blocking and compensatory conditioning in the treatment preexposure effect. Psychopharmacology, 61, 177-189.

Cannon, D., Baker, T., \& Berman, R. (1977). Taste aversion disruption by drug pretreatment: Dissociative and drug-specific effects. Pharmacology, Biochemistry \& Behavior, 6, 93-100.

Cappell, H., LeBlanc, A., \& Endrenyi, L. (1973). Aversive conditioning by psychoactive drugs: Effects of morphine, alcohol and chlordiazepoxide. Psychopharmacologia, 29, 239-246.

Cappeli, H., Leblanc, A., \& Herling, S. (1975). Modification of the punishing effects of psychoactive drugs in rats by previous drug experience. Journal of Comparative and Physiological Psychology, 89, 347-356.

Dacanay, R., \& Riley, A. (1982). The UCS preexposure effect 
in food aversion learning: Tolerance and blocking are drug specific. Animal Learning \& Behavior, 10, 91-96.

Domjan, M., \& Siegel, S. (1983). Attenuation of the aversive and analgesic effects of morphine by repeated administrations: Different mechanisms. Physiological Psychology, 11, 155-158.

Farber, P., Gorman, J., \& Reid, L. (1976). Morphine injections in the taste aversion paradigm. Physiological Psychology, 4, 365-368.

Gamzu, E. (1977). The multifaceted nature of taste-aversion inducing agents: Is there a single common factor? In L. Barker, M. Best, \& M. Domjan (Eds.), Learning mechanisms in food selection. Waco, TX: Baylor University Press.

Heft, M., Daniels, G., Buller, A., \& Riley, A. (1981). Morphine-induced hyperphagia: $A$ behavioral ethogram. Paper presented to Society for Neuroscience, Los Angeles.

Jacobs, W., Zellner, D., LoLordo, V., \& Riley, A. (1981). The effect of post-conditioning exposure to morphine on the retention of a morphine-induced conditioned taste aversion. Pharmacology, Biochemistry \& Behavior, 14, 779-785.

Kamin, L. (1969). Predictability, surprise, attention and conditioning. In B. A. Campbell \& R. M. Church (Eds.), Punishment and aversive behavior (pp. 279-298). New York: AppletonCentury-Crofts.

Randich, A., \& LoLordo, V. (1979). Associative and non-associative theories of the UCS pre-exposure phenomenon: Implications for Pavlovian conditioning. Psychological Bulletin, 86, 523-548.

RrLeY, A., JacoBs, W., \& LoLordo, V. (1976). Drug exposure and the acquisition and retention of a conditioned taste aversion. Journal of Comparative and Physiological Psychology, 90, 799-807.

Riley, A., Jacoss, W., \& LoLondo, V. (1978). Morphine-induced taste aversions: A consideration of parameters. Physiological Psychology, 6, 96-100.

Roscoe, J. (1975). Fundamental research statistics for the behavioral sciences. New York: Holt, Rinehart and Winston.

Rudy, J., Iwens, J., \& Best, P. (1977). Pairing novel exteroceptive cues and illness-induced taste aversions. Journal of Experimental Psychology: Animal Behavior Processes, 3, 14-25.

Schnur, P., Bravo, F., Trujillo, M., \& Rocha, S. (1983). Biphasic effects of morphine on locomotor activity in hamster. Pharmacology, Biochemistry \& Behavior, 18, 357-361.

Siegel, S. (1976). Morphine analgesic tolerance: Its situation specificity supports a Pavlovian conditioning model. Science, 193, 323-325.

Siegel, S. (1978). Tolerance to the hyperthermic effect of morphine in the rat is a learned response. Journal of Comparative and Physiological Psychology, 92, 1137-1149.

Siegel, S., Hinson, R., \& Krank, M. (1978). The role of predrug signals in morphine analgesic tolerance: Support for a Pavlovian conditioning model of tolerance. Journal of Experimental Psychology: Animal Behavior Processes, 4, 188-196.

Skla R, L., \& Aмiт, Z. (1978). Tolerance to high doses of morphine: Lack of evidence of learning. Behavioral Biology, 22, 509-514.

Stewart, J., \& Eikelboom, R. (1978). Pre-exposure to morphine and the attenuation of conditioned taste aversion in rats. Pharmacology, Biochemistry \& Behavior, 9, 639-645.

WILLNER, J. (1978). Blocking of a taste aversion by prior pairings of exteroceptive stimuli with illness. Learning \& Motivation, 9, 125-140.

(Manuscript received December 22, 1983; revision accepted for publication April 17, 1984.) 